\title{
The Scientific Work of Joseph Priestley
}

\section{By Prof. J. R. Partington, m.B.E.}

$\mathrm{P}$ RIESTLEY'S most important scientific work was the result of a further development of the experimental technique available in his day for the manipulation of gases. This led him to the discovery of a number of new gases, and the creation of a special branch of chemistry called in the older books "Pneumatic Chemistry". The ascertained facts enabled Lavoisier to make such changes in the theory of chemistry that he may fairly be called the founder of the science as we know it to-day.

The existence of gases with characteristic properties was known before Priestley's time. Van Helmont, about 1620 , had recognised the existence of at least two gases different from air, gas sylvestre (carbon dioxide) and gas pingue (hydrogen

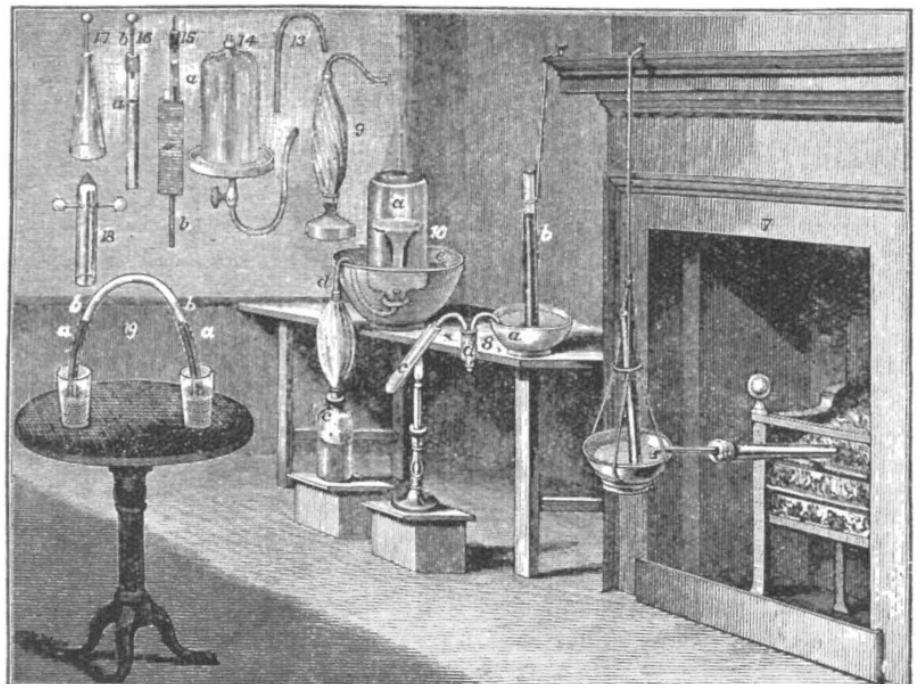

FIG. 1. Part of Priestley's Iaboratory. From “Experiments and Observations on Different Kinds of Air".

or hydrocarbons), and had invented the name gas, derived from chaos, which Priestley did not use. Van Helmont did not succeed in collecting gases; when the materials generating a gas, a process previously called "intestine fermentation", were sealed up in a glass vessel, the latter was "filled with plentiful exhalation (yet an invisible one) and however it may be feigned to be stronger than iron, yet it straightway dangerously leapeth asunder into broken pieces".

Hydrogen was first collected from iron nails and dilute acid in an inverted bottle by Boyle: "the cavity of the glass was possessed by the air, since by its spring it was able to hinder the liquor from regaining its former place". Boyle also showed that hydrogen was combustible and would not burn without air. A little further progress in the manipulation of gases was made by Mayow (1674), and Stephen Hales ("Vegetable Staticks", 1727) collected over water in an inverted globe the "air" given off when all kinds of substances, such as saltpetre and coal, were heated in a gun barrel, or when sulphuric and nitric acids acted on metals. Hales measured these airs and then apparently threw them away without examining their chemical properties, regarding them all as modified air. His severely quantitative technique seems to have been influenced by the writings of Newton who, as Priestley says, "as he had very little knowledge of air, so he had few doubts concerning it". Cavendish in 1766 collected fixed air (carbon dioxide), discovered by Black in 1754 , over water and mercury, and carefully investigated its properties, as well as those of inflammable air (hydrogen), discovered by Boyle. He used drying tubes and determined the densities and the solubilities of the gases in water and alcohol. The first use of mercury for collecting soluble gases is incorrectly attributed by Kopp to Priestley.

Cavendish's pneumatic trough had no shelf, a fitting introduced in a crude form by William Brownrigg, of Whitehaven, whose paper appeared in 1765, although it had been communicated to the Royal Society twentyfour years previously and was known to Hales and probably to Cavendish. Scheele, who used very simple apparatus and collected the gases in bladders (as did Cavendish) as well as jars, carried out his investigations from 1770 to 1772 (or 1773), but the work was not published until 1777, so that Priestley's discovery of oxygen in 1774 was made independently of Scheele's work.

Priestley's researches on gases were initiated by a chance event. In 1768 he lived at Leeds near what he calls a public brewery, and began to make experiments on the fixed air, "of which there is always a large body ready formed, upon the surface of the fermenting liquor". He showed that it could be absorbed by water to make an artificial Pyrmont water, and devised an apparatus for producing it from chalk and oil of vitriol, his supply at the brewery having been cut short by an unfortunate experiment in which a vat of beer was spoiled. He thought the reason for the turbidity produced in lime water by air in which a candle had burnt out was that "flame disposes the common air to deposit the fixed air it contains", an inability to furnish a correct explanation for a good experiment which is typical of his work from first to last.

Priestley took as his guide in chemical experiments a theory which he found exclusively professed by the chemists of his day, that reversion to the conceptions of Plato and Aristotle called the theory of phlogiston. He has been reproached for his use of this theory, but clearly unjustly, 
since the theory was as inextricably entangled in the scientific thought of the eighteenth century as that of the ether a century later or the electron to-day. Macquer, writing in 1778, refers to it as "the surest guide we can take in chemical experiments" ; Fourcroy continued to teach it until 1786-87 and Berthollet until 1785. Cavendish, a man of the highest intellectual capacity, believed in it, so far as we know, until his death in 1810, and Priestley still defended it in his last work, "The Doctrine of Phlogiston Established", in 1800 and 1803 . It persisted in Germany after this. It is too much to expect a Laocoon to throw off such coils; a Hercules such as Lavoisier was necessary.

The researches on gases carried out by Priestley are collected in six volumes of "Experiments and Observations on Different Kinds of Air" (1774-86 ; abridged in three volumes, 1790 ; a modern abridgement in one volume for the use of students is much to be desired). Its title is correct, and the work itself reveals clearly the progress made by the mind and hands of the great experimenter. The results are given in the order in which they were found, as in Faraday's publications, and the apparent lack of order, systematisation and condensation, which intrudes on the attention of a hurried reader, is responsible for the incorrect judgment of the historians of chemistry, that Priestley was a hasty and careless worker. $\mathrm{He}$ certainly left too many experiments unfinished and failed to follow up many interesting results. His range of tests was too restricted, a lighted candle and a living mouse being his favourite 'reagents'.

Priestley's apparatus was simple, being, as he says, "nothing more than the apparatus of Dr. Hales, Dr. Brownrigg and Mr. Cavendish, diversified and made a little more simple". He worked in the midst of his family and Fig. 1 shows his laboratory. A substance is being heated in a gun barrel in the fire, the evolved gas being collected in a suspended pneumatic trough over mercury. A substance in the tube $8 c$ is heated by a candle and the gas, after passing through a trap $d$ to separate any liquid carried over, is collected over mercury in $8 \mathrm{~b}$. In 10 , a gas evolved in the bottle $c$ is collected over water, passing through a bladder on the way so as to allow of the bottle being agitated, rubber tubing being then unknown. Some apparatus is shown on the chart at the back, and 19 is a piece of apparatus for passing electric sparks through a gas, as used by Cavendish.

The pneumatic trough, which is in its modern form, and auxiliary apparatus, are shown in Fig. 2. The trough, which is provided with a fixed shelf, contains water. The jars $c, f$ and $d$ stand on the shelf $b b$, the jar $c$ receiving gas from the bottle $e$ fitted with a bent glass delivery tube. In the inverted glass $d$ is a mouse, these animals being kept in the arrangement 3 . The jar $f$ contains a cup supported on a wire stand, also shown in 5; in the cup a substance may be exposed to the gas and if necessary heated by a burning glass. A plant is shown growing in the gas jar 2, and other small pieces of apparatus may be seen. The mice used were kept on "a shelf over the kitchen fireplace where, as is usual in Yorkshire, the fire never goes out'". They live, he found, entirely without water and when passed through water "they require and will bear a very considerable degree of heat to warm and dry them".

With such apparatus Priestley investigated the properties of fixed air and inflammable air, discovered three gaseous oxides of nitrogen, ammonia gas (alkaline air), hydrogen chloride (acid air), sulphur dioxide (vitriolic acid air) and silicon fluoride (fluor acid air). The experiments on the oxides of nitrogen are particularly detailed and interesting. 
mice and myself have had the privilege of breathing it". He suggested the use of oxygen in cases of pneumonia, and in the production of high temperatures.

Priestley believed in rapid publication, as did Faraday: "a person who means to serve the cause of science effectually, must hazard his own reputation so far as to risk mistakes in things of less moment", and all his results were available without delay to others, who could make better use of them than he could himself.

In August 1771 Priestley had found that vegetation, such as growing mint, spinach and groundsel, restores air vitiated by burning candles or by the breathing of animals: "the injury which is continually done to the atmosphere by the respiration of such a large number of animals . . . is, in part at least, repaired by the vegetable creation". In 1778 he found that water plants growing in water containing fixed air evolve oxygen. The part played by light in the process of photosynthesis, although known to Priestley, was more fully worked out by Ingen-Houss in 1779 .

Another "random experiment", made in 1781, in which moisture was found to result from the explosion of a mixture of common air and inflammable air, led to Cavendish's research on the formation of water from hydrogen and oxygen. In Priestley's own extension of this work, considerable confusion and error resulted from his neglect to distinguish clearly between hydrogen and other combustible gases, such as carbon monoxide and hydrocarbons. This confusion remained until about 1800, when Cruickshank, of Woolwich, cleared up the matter.

Neither Priestley nor Cavendish was able to draw correct conclusions from his experiments. This was reserved for Lavoisier, "a great architect, who laboured little in the quarry" in the obscurity of which the two experimenters worked. Priestley never professed to be a chemist, and in the full sense of the word never was. His range of knowledge was too restricted, and he was thus incapable of appreciating the correct interpretations of his experiments when they were clearly placed before him.

Priestley's mind was powerful and broad: he was a good classical, oriental and modern linguist, who was able to argue points of theology with more orthodox divines with the scriptures in the original languages. He also had read extensively in philosophy and theology, and became involved in politics. His days became more and more occupied with these pursuits and he was the object of a growing animosity which finally hounded him from England to America, where he died. Although his experimental work imposed itself with unescapeable mastery on contemporary science, his theoretical contributions were negligible. Careful scientific thought does not flourish in such an environment.

No adequate account of Priestley's work in physics seems to be available. He published in 1767 a "History of Electricity", a subject which he calls his "favourite amusement". The experiments in electricity were begun at Nantwich and the book written in Warrington, with the encouragement of Benjamin Franklin. It contains an excellent account of early work in electricity and some new experiments, as well as the argument that electric forces obey an inverse square law because of the absence of charge inside a hollow conductor. In two papers published in 1769, "On the Lateral Force of Electric Explosions", he showed that a discharge from a Leyden jar when sent through a circuit composed of a metal chain with the ends brought together so as to form a small air gap, would in part jump the air gap of high resistance rather than pass through the metallic loop. In 1772 appeared two volumes on "The History and Present State of Discoveries Relating to Vision, Light and Colours", which were not so well received as the history of electricity.

"Human happiness", Priestley tells us in a characteristically discursive preface to the "History of Electricity", "depends chiefly upon having some object to pursue, and upon the vigour with which our faculties are exerted in the pursuit". He was happy in having several objects for the exercise of his vigorous and original mind. In science he was a great explorer, opening out in his rapid and fortunate survey a great number of sites, the rich treasures of which he left to others, equipped with greater patience and knowledge, to remove, arrange, classify and interpret. Such a pioneer fills a place in the annals of human achievement, and such a one was Joseph Priestley, the bicentenary of whose birth we now gratefully remember.

\section{Priestley's Associations with London}

\section{By H. G. WAYLING}

JOSEPH PRIESTLEY knew London well. Although he officiated for several years as a Dissenting minister at Nantwich and at Leeds, before coming to reside in London as Lord Shelburne's librarian, yet he generally managed to spend a month every year in the metropolis. His friendship with men like Benjamin Franklin, Dr. Richard Price, John Canton and Andrew Kippis encouraged him, while still a provincial pastor, to study natural philosophy earnestly. He speaks of the happy hours spent in their company at the London Coffee House on Ludgate Hill, the back premises of which abutted on to the Old Sessions House in Newgate. Over their cups, these philosophical enthusiasts discussed topical questions and laid plans for prospective publications.

A few yards higher up Ludgate Hill in St. Paul's churchyard, lived Joseph Johnson, the bookseller 